\title{
Human Capital accumulation AND INVESTMENT BEHAVIOUR
}

Danilo Cavapozzi, Alessio Fiume, Christelle Garrouste, Guglielmo Weber

๑ Mea-Mannheim Research Institute for the Economics of Aging

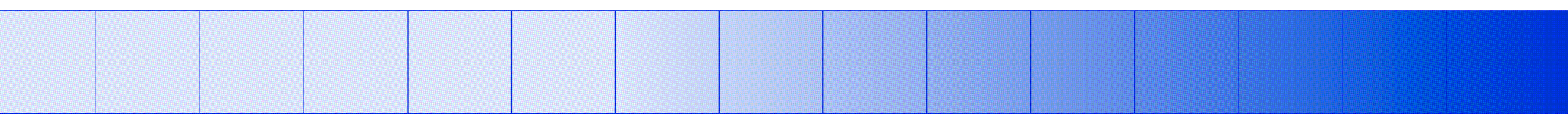

L13, 17_D-68131 Mannheim_Phone +49 621 181-2773/1862_Fax +49 621 181-1863_www.mea.uni-mannheim.de 


\title{
4 Human Capital Accumulation and Investment Behaviour
}

\author{
Danilo Cavapozzi \\ Dipartimento di Scienze Economiche "Marco Fanno" \\ Università di Padova \\ Alessio Fiume \\ Dipartimento di Scienze Economiche "Marco Fanno" \\ Università di Padova \\ Christelle Garrouste \\ European Commission Joint Research Center \\ IPSC - Econometrics and Applied Statistics Unit \\ Guglielmo Weber \\ Dipartimento di Scienze Economiche "Marco Fanno" \\ Università di Padova
}

\subsection{Limited participation in financial markets}

Limited use of financial markets is associated with financial distress later in life (Angelini, Brugiavini and Weber, 2009). Such limited use may be the result of choice, or, more likely, it may be due to some impediment.

Limited participation in financial markets may be related to transaction costs or high risk aversion, but has also been found to be related to a low level of financial literacy. A number of papers have used explicit and quantitative measures of financial literacy and related them to individual financial decisions (e.g., Guiso and Jappelli, 2008; Lusardi, 2008). Lusardi and Mitchell (2007) show that more 'financially literate' individuals are more 'retirement ready'. It has also been shown that stock holdings are much less common among the less financially literate (Christelis, Jappelli and Padula, 2010; McArdle et al., 2009).

Although no direct measure of financial literacy is as yet available in SHARE, we have information on education-related variables that are well known to correlate with financial literacy. In particular, the third wave of SHARE records information not only on educational attainment, but also on self-assessed mathematical ability while at school and on access to books at age ten. Crucially, we also know when an individual first entered risky financial markets, by investing in stocks, mutual funds, individual retirement plans or life insurance policies.

This chapter is divided in five sections including the current introduction. The second section presents the distribution of the types of investment in risky assets and the entry age into these financial markets across Europe; the third section introduces the different human capital components retained for our analysis. The 
fourth section presents the results of the multivariate duration analysis conducted to investigate the relationship between investment behaviour and human capital accumulation. Finally, the fifth section draws the main conclusions of our analysis.

\subsection{When did older Europeans first invest?}

It is a well known fact that large fractions of individuals do not own risky financial assets, thus foregoing the extra returns that these assets have so far produced in the long run. The third wave of SHARE asks whether individuals ever owned stocks, mutual funds, individual retirement accounts or life insurance policies. If the answer is yes, respondents are asked to report when they first bought them. The fractions of individuals who answer yes is relatively small overall (24\% for stocks, $22 \%$ for mutual funds, $26 \%$ for individual retirement accounts, $31 \%$ for life insurance policies), but varies dramatically across countries. For instance, over $50 \%$ of Swedes and Danes report holding stocks at some time over their life course, less than $15 \%$ do the same in Austria, Italy, Spain, Greece and Poland. Mutual funds investment follows a similar pattern - with lower participation rates in most countries (Sweden, Germany, Belgium, France and Switzerland are the exceptions). Investment in individual retirement accounts instead reflects much more special features of pension legislation: we observe high values in the Czech Republic (56\%), Sweden (53\%), France (49\%), Belgium (46\%) and Switzerland $(42 \%)$, and low or very low participation rates in all remaining countries. Finally, life insurance policies are wide-spread in Sweden, Germany, and Austria (all above $40 \%$ ), and rather common also in Poland (31\%), where they were quite wide-spread under the communist regime. Life insurance policies are sometimes required by lenders when mortgages are taken up. For this reason, we have excluded them throughout the analysis if their purchase coincides with the purchase of a home (+/- 1 year around it).

Figure 4.1 plots the fractions of individuals who ever had at least one of the above forms of risky financial investment at some stage in their lives. This fraction is highest in Sweden (91\%) and Denmark (80\%). It also exceeds $60 \%$ in Switzerland, Germany, Belgium, France and the Czech Republic. The lowest values are recorded in Greece (11\%), Spain (25\%), Italy (28\%) and Poland (34\%). 
Figure 4.1: Fraction of individuals who report ever investing in at least one risky financial asset

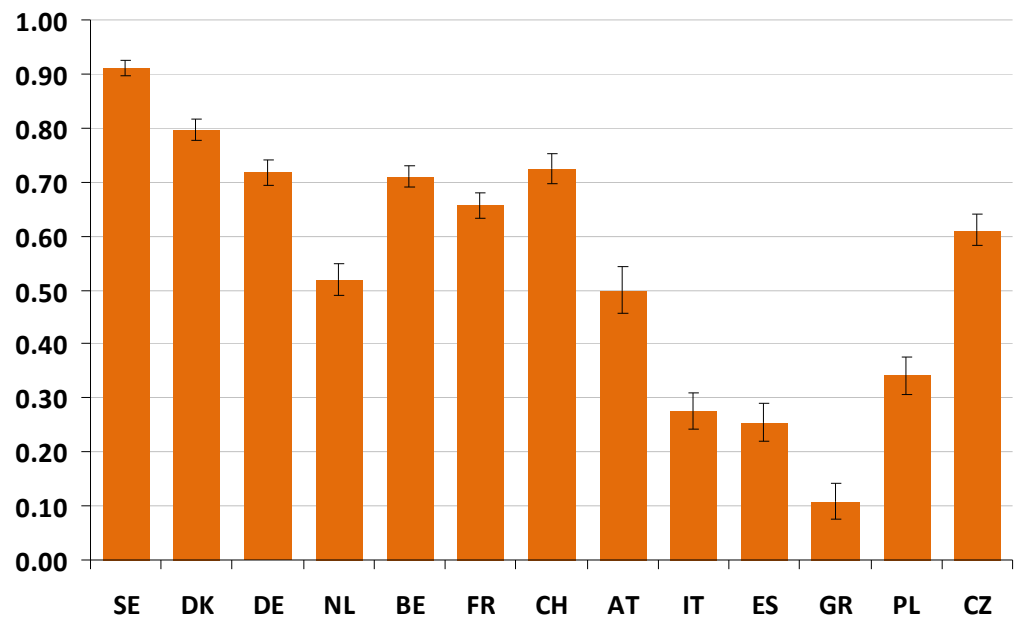

Participation rates differ by gender: overall, $60 \%$ of men and $47 \%$ of women ever invested in at least one risky financial asset. Gender imbalance is lowest in Sweden (93-90), the Czech Republic (63-59) and Poland (37-31), highest in absolute terms in Germany (82-63), the Netherlands (64-42) and Switzerland (84-63). Of the remaining countries, Spain (31-21) and Greece (15-7) have lower differences, partly because both sexes exhibit low participation. These gender differences in investment behaviour are confirmed by other studies which highlight the overall higher risk-aversion of women (e.g., Hira and Loibl, 2008).

Participation rates are also driven by institutional factors. For instance, the high participation rate of Czech respondents is largely driven by their retirement accounts (which have been heavily tax-subsidized since 1995): only $23 \%$ report ever having held stocks or mutual funds. As displayed in Figure 4.2, the exclusion of retirement accounts has otherwise minor effects on participation. It is worth stressing that in some countries (like the Netherlands or Sweden) individuals have a say in the way their occupational pensions are invested, very much like in an individual retirement account. 
Figure 4.2: $\quad$ Fraction of individuals who report ever investing in risky assets by asset type

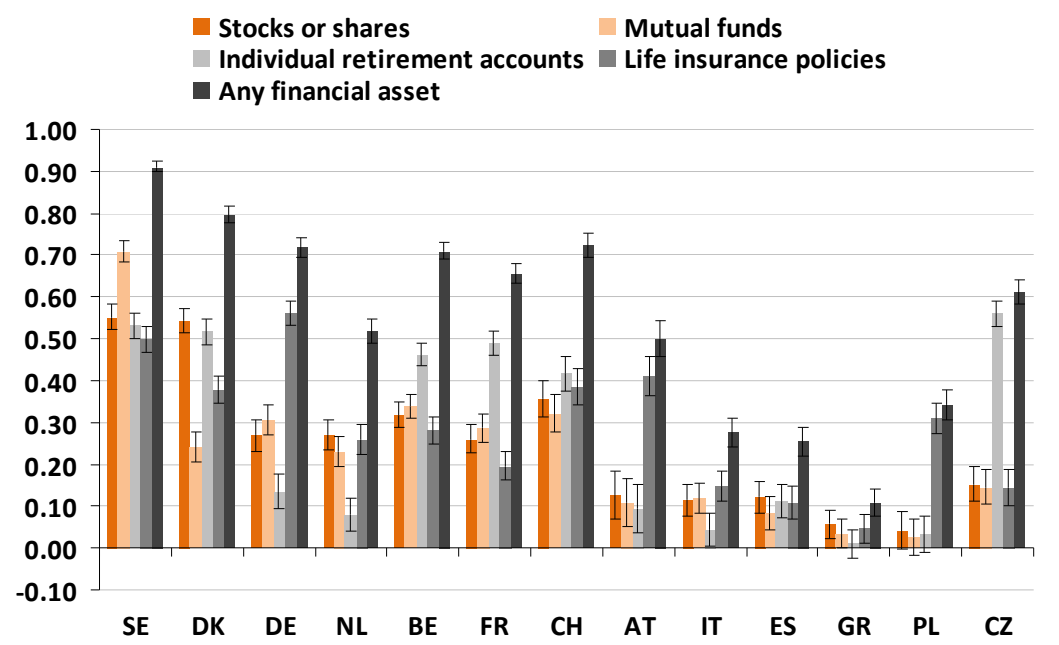

To better understand the above distribution of risky financial assets among older Europeans it is useful to investigate at what age the first investment was made. Figure 4.3 displays the age distribution of first-time investment in risky financial assets. The left panel excludes life insurance policies. Not surprisingly, most respondents report starting participation at age 40 or above, with a peak at 50 . However, there are non-negligible fractions of first-time investors at younger ages. Given that our respondents were all at least 52 years of age at the time of the interview, those who first invested at ages below 35 must have entered the market before the 1990s. The right panel includes life insurance policies: in this case, investment early in life is much more common. Indeed, some individuals report investing in their teens (possibly for tax avoidance purposes). Note that mortgagerelated life insurance policies are not counted here (see above). 
Figure 4.3: Fraction of individuals who first invested by age. Life insurance policies excluded in the left panel, included in right panel
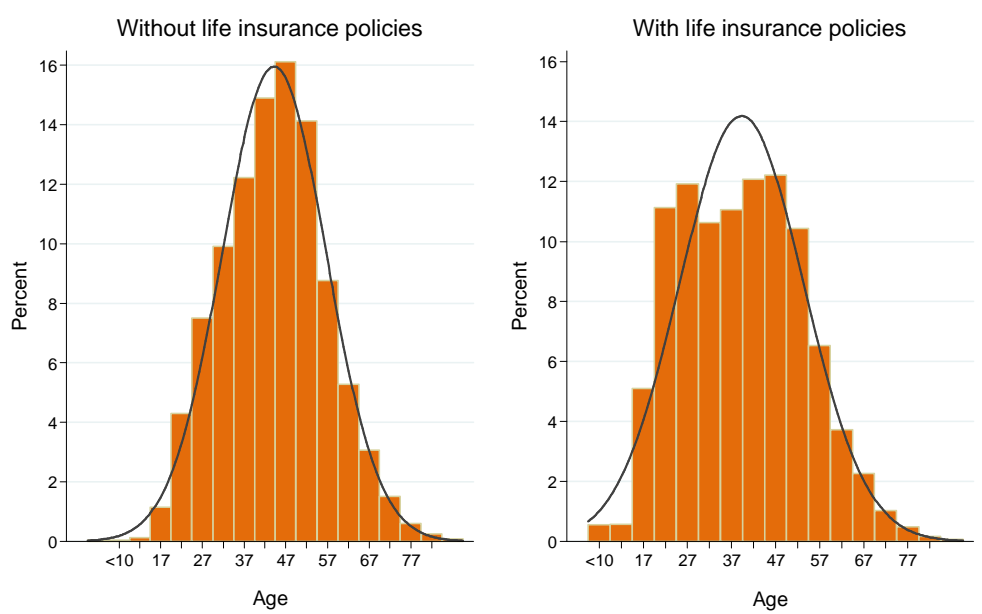

Figure 4.4: Fraction of individuals who first invested in financial markets, by age and country
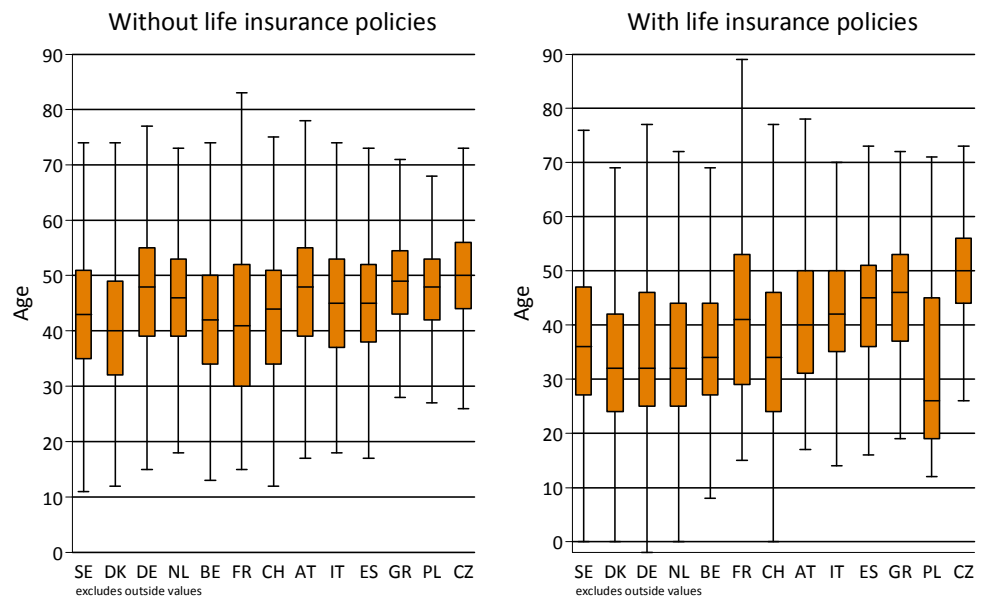

Figure 4.4 provides details on the age distribution of financial markets entry by country. For each country, it displays the median, the first and third quartiles, the minimum and maximum. Life insurance policies are excluded in the left panel, in- 
cluded in the right panel. We see in the left panel that the median is lowest in Denmark and France, followed by Belgium, Sweden and Switzerland. France is the country with the largest dispersion (as proxied by the interquartile range), Poland and Greece with the lowest. In interpreting these statistics one has to keep in mind that they refer to the density functions conditional on participation: if marginal investors tend to enter later in life, the higher participation rate in Sweden (over $80 \%$ ) may explain why the median age of entry is higher than in France, where fewer participate (less than $60 \%$ ). The right panel shows that the highest dispersion is attained in Poland, followed by Germany, Switzerland and the Netherlands, highlighting the importance of life insurance policies in promoting early entry into financial markets.

\subsection{The role of human capital accumulation}

Human capital is one of the most important determinants of investment decisions. Indeed, higher human capital endowments may lead to a better understanding of financial market opportunities and help individuals in realizing efficient portfolio allocations (Christelis et al., 2010). SHARELIFE data make it possible to analyze human capital along several dimensions (i.e. formal education level, mathematical skills and cultural background) and are of use to investigate whether the crosscountry heterogeneity in financial market participation discussed in the previous section can be associated with cross-country heterogeneity in human capital accumulation.

Figure 4.5: $\quad$ Years of full time education by country

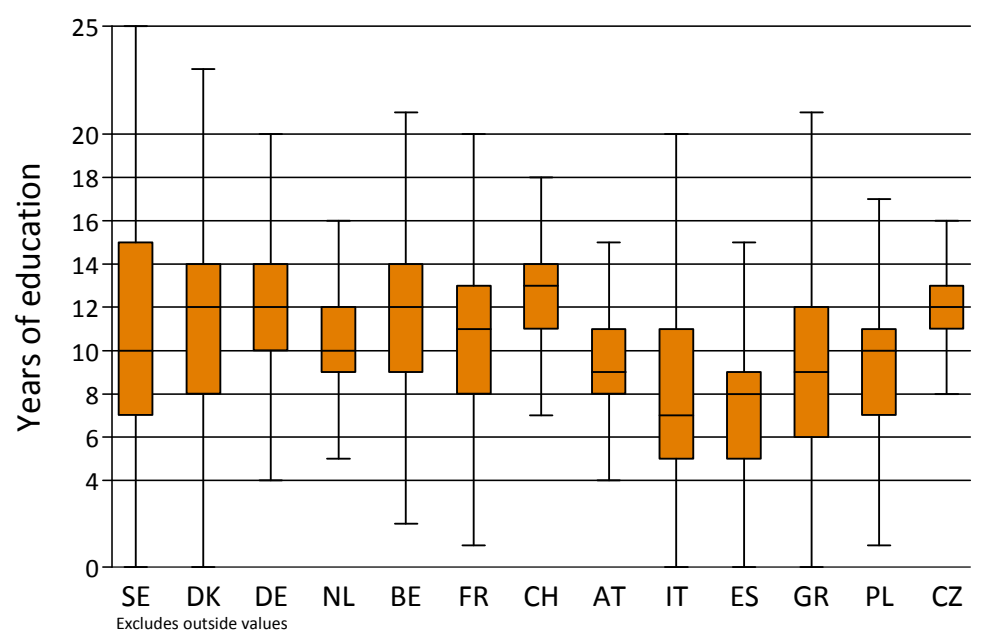


First, we consider the number of years of education, as a proxy of formal education level. Our analysis makes use of context information to take into account that primary school ages vary over time and across countries. As reported in Figure 4.5 , we find much lower median education levels in Spain, Italy, Austria and Greece. Respondents in Denmark, Germany, Belgium, Switzerland and the Czech Republic remain in full time education longer. The greatest variability occurs in Sweden, Greece, Italy and Denmark - by far the lowest in the Czech Republic. These patterns largely reflect the education reforms on duration of compulsory schooling that took place over the past century (Garrouste, 2010), inequalities in the economic resources available during childhood but also individual choice and society attitudes towards education. For instance, median years of education tend to be lower for women in all countries, but in some countries gender differences are particularly strong: we find that in Denmark, Switzerland, Greece and Italy the median number of years of education is lower for women by at least two years.

Although there is no doubt that the number of years of full-time education is a key indicator of human capital, the understanding of economic and finance concepts required to manage risky assets is more strictly related to mathematical skills (McArdle et al., 2009). To this end we take advantage of the SHARELIFE question asking respondents to evaluate their mathematical skills at the age of ten as compared to their class-mates. Such self-assessment to some extent reflects individuals' self-confidence. We find that, overall, while more than 30 percent of individuals rank themselves better in mathematics than their class-mates, less than 15 percent declare themselves worse. According to the majority of respondents, their understanding of mathematics was about the same as that of their classmates.

In previous waves of SHARE respondents provided answers to four numeracy questions that help us assess their current mathematical skills in a less subjective way. In our analysis we therefore combine the information on years of education, self-assessed mathematical skills at the age of ten and the number of correct answers to numeracy questions. It is interesting to see how these variables co-vary across countries. In Figure 4.6 we report the average numeracy score versus the average self-assessed mathematical abilities at age 10 by education and country. This figure reveals that there is a strong positive relation between mathematical skills at age 10 and educational attainment, but also that current numeracy is positively correlated both with early life mathematical skills and with formal education. It also shows that on average, in some countries, notably Italy and Spain, but also Poland and France, current numeracy is lower after controlling for education. This may reflect more limited use of mathematical skills in adult life or the type of formal education received. Moreover, it is worth highlighting that the 1960s were marked by an overall international progressive shift towards constructivist mathematics curricula, i.e. a shift in focus from memorization to understanding, launched in the United States. Yet, whereas Switzerland and northern Europe (including Sweden, Denmark and the Netherlands) adopted the new approach 
promptly, the southern and eastern Europe kept on with the traditional memorization approach until the mid-1980s (Garrouste, 2010). Hence, the dispersion of the countries along the correlation trend line (Figure 4.6) may also be affected by the differences in teaching methods of mathematics at the age of 10.

Figure 4.6: Average current mathematical ability versus mathematical skills at age ten, by education and country

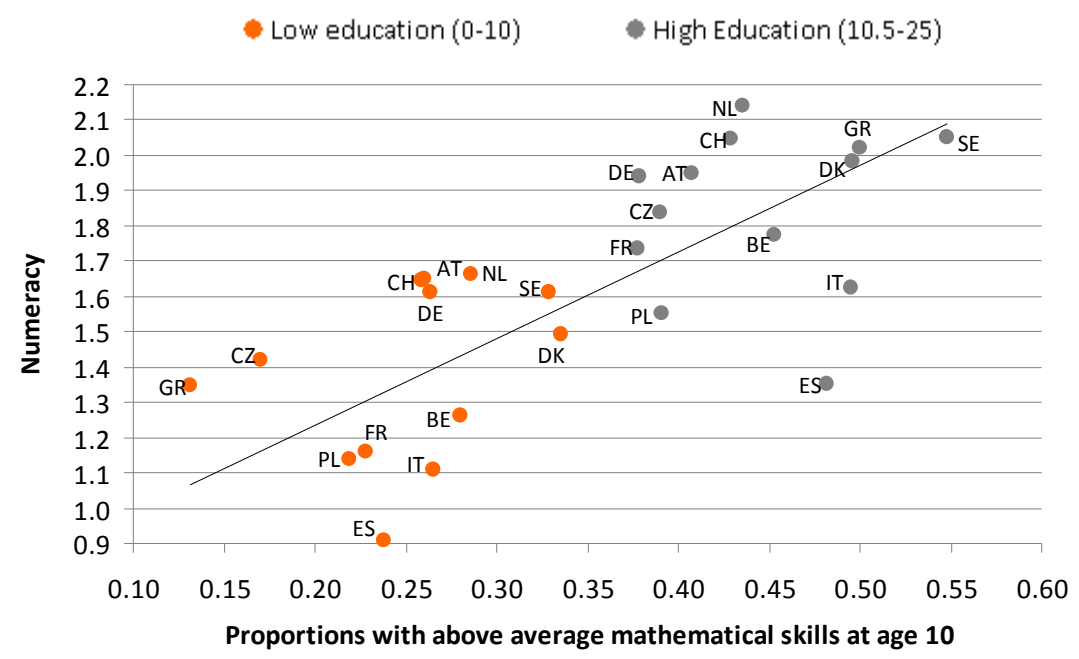

Finally, we consider the cultural background of parental household by looking at the number of books in the accommodation at the age of 10 . This is expected to be an indicator of the average education level of household members and also of respondents' educational attainments. A wide research strain (OECD, 2010) shows that there is persistence in the socio-economic status across generations. For instance, growing up in a better educated environment is expected to be positively correlated with human capital formation. Indeed, better educated households are more likely to be better off and thus to invest more in their children's education. Almost two thirds of SHARELIFE respondents declare that there were not enough books to fill one shelf (at most 25 books) in their accommodation at the age of 10 . However, there are wide cross-country differences showing that Sweden, Denmark, Switzerland and the Czech Republic present the highest levels of book provision, while Mediterranean countries and Poland show the lowest (for more details, see Cavapozzi, Garrouste, and Paccagnella, in Chapter 3 of this volume).

This descriptive analysis shows that there is cross-country heterogeneity in human capital accumulation. Remarkably, Scandinavian countries exhibit high participation to financial markets, low entry-age and high levels of human capital. On the contrary, Mediterranean countries are characterized by a lower propensity 
towards risky investments, higher entry-age in financial markets and lower levels of human capital indicators.

The next section will investigate the relationship between investment behaviour and human capital accumulation in a multivariate framework. On the one hand, we want to show whether cross-country heterogeneity in investment behaviour remains sizeable when controlling for individual characteristics. On the other hand, we will ascertain whether human capital indicators are significantly related to the decision of investing in risky assets if considered jointly and when allowing for cross-country differences in the institutional framework.

\subsection{Multivariate duration analysis}

We run a duration analysis to investigate how the timing of the first investment in risky assets is related to individual and household characteristics. Duration models have the advantage of combining the information coming from both individuals who actually invested in risky assets and those who have not entered financial markets yet. The alternative strategy, of focusing attention solely on the elderly who have had risky assets, may suffer from endogenous sample selection problems, particularly for Mediterranean countries, where financial market participation is low, as shown in Figure 4.1. However, all of our analysis is conditional upon survival: to the extent that the poor die younger this may lead to biased estimates even in the context of duration analysis models.

The set of explanatory variables used in our regression includes a variety of individual characteristics: country of residence, gender, year of birth, years of education, self-assessments of mathematical skills at the age of 10, number of books in the accommodation at the age of 10 and current monthly household income. In addition, we use previous waves of SHARE data to take into account respondents' answers to four numeracy questions available in the questionnaire. As explained in the previous section, such numeracy indicators complement the self-evaluations of mathematical skills at the age of 10 since they are collected when respondents are $50+$ and allow having two distinct measures of ability in mathematics at different stages of the life-cycle. 
Figure 4.7: Probability of having never invested in risky assets by age for Sweden, France, Austria and Italy, controlling for birth cohort, gender, education, income, numeracy, mathematical skills and number of books at the age of 10

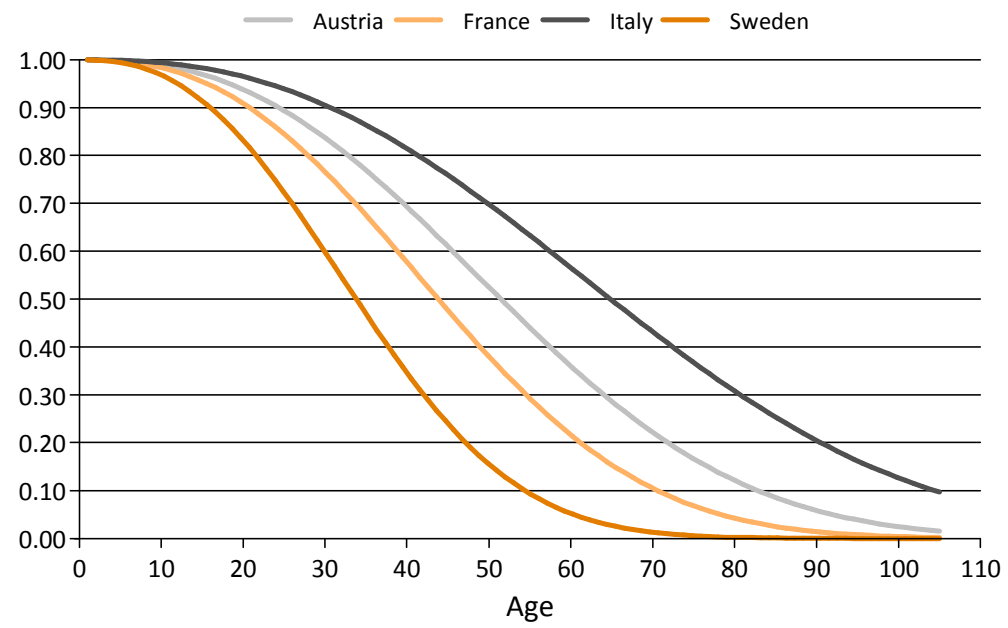

Our results show that cross-country differentials in the access to financial markets are statistically significant even after conditioning on further individual characteristics related to investment behaviour. Ceteris paribus, Swedes and Danes invest in risky assets earlier. On the contrary, respondents in Italy, Spain and Greece tend to delay their first risky investment. Hence, at a given age, the probability of having never invested in risky financial markets is lower in Scandinavian countries and higher in Mediterranean countries. We use our estimates to calculate the probability of having never invested in risky assets and show how it varies with age. Figure 4.7 summarizes our results. For simplicity sake we show the results only for Sweden, France, Austria and Italy because they summarize the spatial patterns in Europe and in particular the North-South gradient in access to financial markets. For each year of age (reported on the x-axis) this figure reports the probability of having never invested in risky financial markets up to that time. Overall, the probability of having never held risky assets decreases with age in all countries. However, we notice that it is highest for Italy and lowest for Sweden at any age. France and Austria lie in the middle, but the former is much closer to Sweden than the latter.

The number of years of education is an important predictor of the timing of the first risky investment. Those who remain in full-time education longer anticipate the decision of entering financial markets. This result is in line with the hypothesis that education helps understanding the opportunities offered by risky assets via a positive impact on financial literacy. It should be kept in mind that we included monthly household income among the explanatory variables precisely to explicitly 
take into account that education might additionally affect investment decisions via an income effect. As displayed in Figure 4.8, at any age, the higher the number of years of education, the lower is the probability of having never invested in risky assets. The widest gap is found comparing those who spent at most 6 years in full time education with those who remained in full time education longer.

Figure 4.8: Probability of having never invested in risky assets by years of education, controlling for income, numeracy, mathematical skills, birth-cohort, gender, country effects and number of books in the accommodation at the age of 10

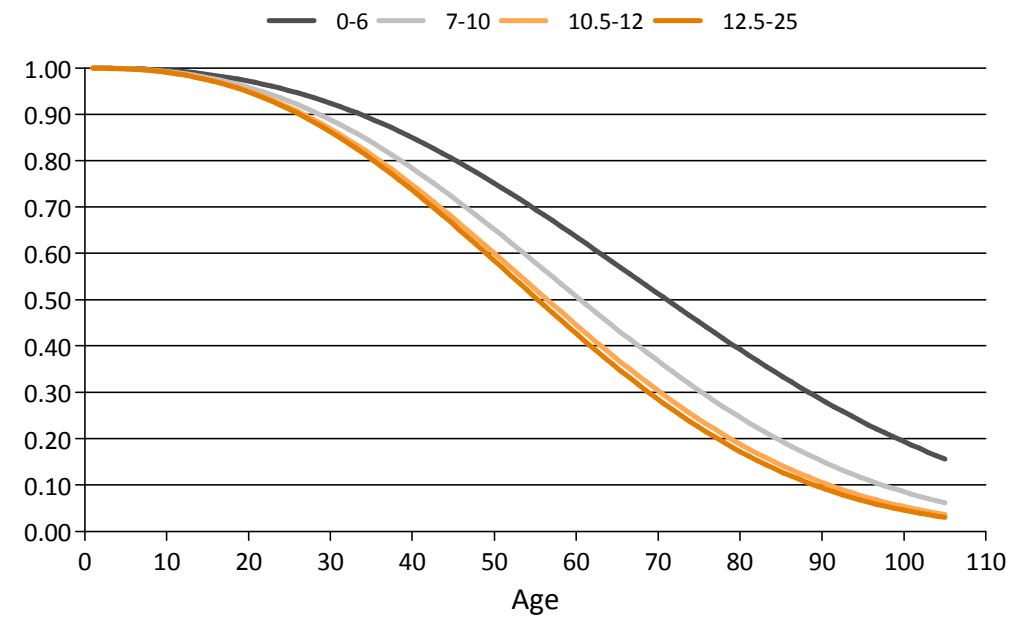

Moreover, individuals with higher mathematical and numeracy skills invest in risky assets earlier. Both indicators consistently show that those who have better numeracy skills anticipate their entry in financial markets. This pattern highlights the crucial role played by mathematics in promoting early financial markets participation, possibly by enhancing the necessary self-confidence in one's ability to make the correct choices. Although our analysis is mainly descriptive and the estimation of causal effects is far beyond its scope, our results suggest that improving the access to education and fostering the teaching of mathematics at all levels of compulsory schooling is a possible strategy to make individuals more familiar with financial markets.

We also find that the cultural background plays an important role in determining investment behaviour. As discussed above, we describe cultural background characterizing respondents' childhood by exploiting the SHARELIFE questions about the number of books in the accommodation at the age of 10. Respondents spending their childhood in an accommodation with more books are more prone to enter financial markets earlier. Number of books is an indicator of the educational 
attainments of household members. Given the strong and positive correlation between education and the probability of holding risky assets, it is not surprising that respondents growing up in a better educated and economically dynamic environment anticipate their entry in the financial markets. Indeed, their parents, or other older co-habiting relatives, are themselves more likely to hold risky assets, which may make it easier to gather all the necessary information to understand financial markets and decide to invest in risky assets. Finally, we find that women tend to invest later in life, particularly so when they have low education.

To evaluate the reliability of our empirical results, we calculate for each country the median fitted age of entry into risky financial markets and cross this country-level variable with the ratio between stock market capitalization and GDP, which is a widely used index of financial development (Guiso, Jappelli, Padula and Pagano, 2004). Results are reported in Figure 4.9 (in the case where the predicted value exceeded 100, namely Greece, it was set to 100. Dropping Greece from the analysis makes little difference).

Figure 4.9: Median predicted age of first entry into financial markets versus stock market capitalization/GDP

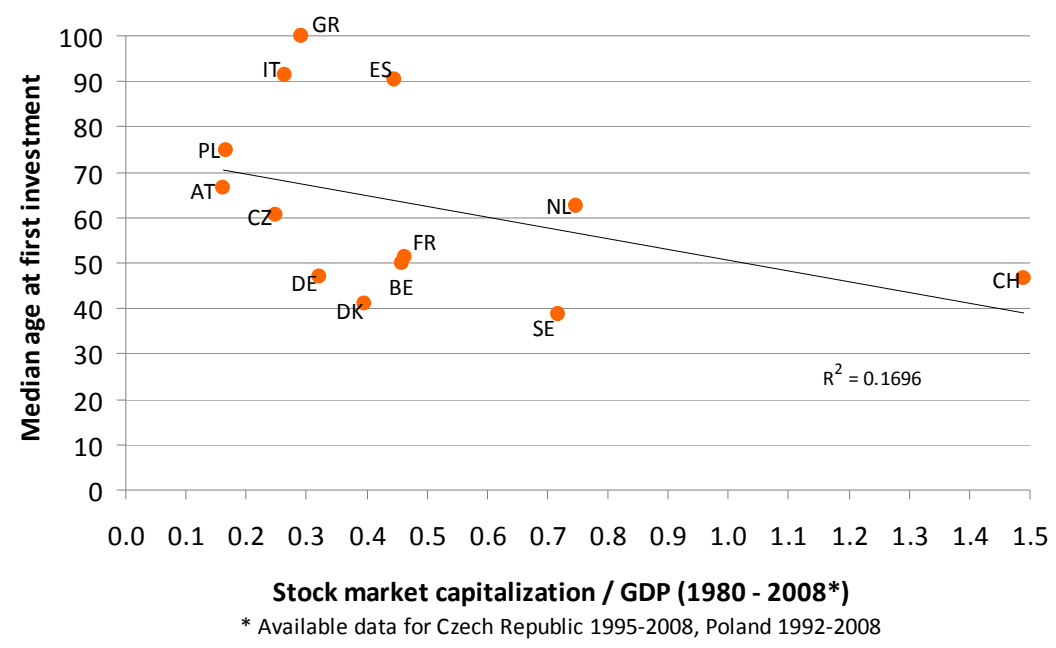

Figure 4.9 shows that there is a clear negative correlation between the age of first risky investment estimated by our model and the development of financial institutions. Although this evidence cannot be conclusive about the causality of this relationship, individuals living in countries where financial markets are less developed delay the decision of investing in risky assets. This is in line with the hypothesis that fostering human capital accumulation might increase the demand for risky financial instruments and contribute to the development of financial markets. 
The fitted median age of first investment is even more strongly correlated with the ratio between life insurance premium volume and GDP. The higher this ratio, the higher is the importance of this type of asset in the economy. If we look at Figure 4.10, we notice that the countries where life insurances are more widespread are also those where the age at first risky investment is lower. In some other countries, notably Italy, Spain and Greece, later entry in financial markets is associated with lower life insurance premium volume. Indeed, in these countries, participation in all financial markets, including life insurance markets, is lower, as documented by Figure 4.2.

Figure 4.10: Median predicted age of first entry into financial markets versus life insurance premium volume/GDP

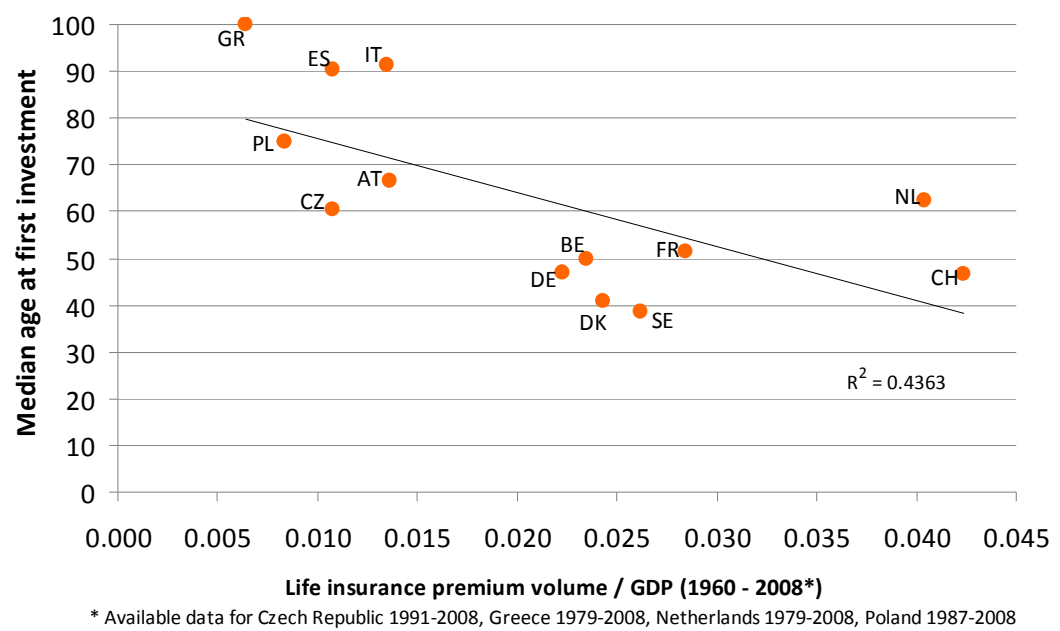

\subsection{Conclusions}

Making correct use of financial instruments plays an important role in securing a good standard of living in old age. People who failed to invest in equity over the last century missed out on spectacular returns, and are now more likely to be in financial hardship.

Our findings that formal education, mathematical skills and family background all play a role in explaining participation to financial markets comforts the assumption that financial behaviour is affected by levels of human capital. The evidence that in some countries both education and financial market participation is lower for women is of particular interest, given the momentous increase in educa- 
tional attainment by young females over the last few decades. All this suggests that greater financial literacy constitutes an achievable aim for welfare systems.

\section{References}

Angelini, V., Brugiavini, A. , \& Weber, G. (2009). Ageing and Unused Capacity in Europe: Is There an Early Retirement Trap? Economic Policy, Vol. 59, pp. 463-508.

Christelis, D., Jappelli, T., \& Padula, M. (2010). Cognitive Abilities and Portfolio Choice. European Economic Review, Vol. 54(1), pp. 18-38.

Garrouste, C. (2010). 100 Years of Educational Reforms in Europe: a contextual database. Luxembourg: Publications Office of the European Union, EUR 24487 EN.

Guiso, L., \& Jappelli, T. (2008). "Financial Literacy and Portfolio Diversification". CSEF Working Paper, No. 212.

Guiso, L. Jappelli, T. Padula, M., \& Pagano, M. (2004). EU Finance and Growth. Economic Policy (October): pp. 523-577.

Hira, T.K., \& Loibl, C. (2008). Gender Differences in Investment Behavior. In J.J. Xiao (Ed.), Handbook of Consumer Finance Research (Part III, pp. 253-270). New York: Springer.

Lusardi, A. (2008). "Household Saving Behavior: The Role of Literacy, Information and Financial Education Programs". NBER Working Paper, No. 13824.

Lusardi, A., \& Mitchell, O. (2007). Baby Boomer Retirement Security: The Roles of Planning, Financial Literacy, and Housing Wealth. Journal of Monetary Economics, Vol. 54, pp. 205224.

McArdle, J., Smith, J., \& Willis, R. (2009). "Cognitive and Economic Outcomes in the Health and Retirement Survey", NBER Working Paper, No. 15266.

OECD (2010). A Family Affair: Intergenerational Social Mobility across OECD Countries. In Economic Policy Reforms: Going for Growth (Part II, Chapter 5). Paris: OECD Publications. 